\title{
Co-disposal techniques that may mitigate risks associated with storage and management of potentially acid generating wastes
}

\author{
M. Gowan Golder Associates Pty Ltd, Australia \\ M. Lee Golder Associates Pty Ltd, Australia \\ D.J. Williams The University of Queensland, Australia
}

\begin{abstract}
A mine tailings disposal facility (TSF) remains a major source of risk for a mining operation. It is in reality the only structure on the mine, together with mine waste dumps, that has to "last forever" after the mining operation ceases. While the normal method of tailings disposal into a TSF is well understood and widely practiced, the alternative methods available using co-disposal may provide significant advantages for mining operations with particular issues or problems.

Constraints on mining such as reduced or limited water supply, the need to recycle more water, higher water quality discharge requirements and post closure risks, are encouraging mine planners to consider alternatives to the traditional methods of mine waste management. One of the options available to planners and operators is the co-disposal of tailings and waste rock, particularly if potentially acid forming, for safer storage.

In this paper, the general types of mine waste storage facilities (e.g. valley, paddock and in-pit storages) and the nature of tailings and waste rock are described, and co-disposal (and co-mingling) techniques to reduce the risks associated with the storage and management of wastes are discussed. The potential benefits of these techniques during operation and mine closure are described.
\end{abstract}

\section{Introduction}

Mining operations have produced wastes since early times. Much of this waste has not been managed well and a fair proportion of these wastes have produced acid and metalliferous drainage (AMD) contamination of surface and ground waters. As more marginal orebodies are exploited, particularly using large open pits, waste volumes are increasing. Societal pressures now demand that the mining industry cleans up its act, eliminating or at least minimising the risks of contamination, requiring the management and control of AMD generation from mining wastes and mining voids.

There are generally two waste streams produced by mining, namely:

- Coarse waste rock that comes directly from the mining operation, which is usually dumped in large above-ground heaps.

- Tailings, a crushed and usually finely-ground waste resulting from the mineral extraction process, which is generally pumped as a slurry into a tailings storage facility (TSF).

While the separate management of potentially acid forming (PAF) waste rock and tailings to limit the formation of AMD is widely practiced, we must continue to look at new methods that may improve the management and possibly reduce the overall cost of disposal of these materials.

This paper examines a method of reducing the production of AMD through the controlled management and placement of the mine waste streams, using the concept of co-disposal.

\section{Tailings disposal}

The various methods used to dispose of and store tailings are first described, examining the shortcomings of each application. 


\subsection{Transport}

With the clear exception of fly ash from power stations, almost all mine tailings are produced in slurry form at the end of the mineral extraction process. While they could be dewatered to allow mechanical transportation (truck or conveyor) this is an expensive process due to their fine-grained nature (generally finer than $0.5 \mathrm{~mm}$ ). Tailings are thus generally pumped as slurries from the process plant to the TSF. The solids content of the tailings slurry varies widely according to the mineral mined. Unthickened slurries range upward from $11 \%$ (unthickened nickel ore beneficiation tailings) to $50 \%$ for gold tailings. With conventional thickening a 30\% slurry is typically achieved for coal tailings, while slurries of $58 \%$ are achieved for copper. Slurry solids contents of over $75 \%$ solids are achievable for some tailings using deep tank (paste) thickeners.

\subsection{Tailings containment}

The easiest, and often the cheapest, form of disposal is to pump the tailings into a pre-formed containment, a tailings storage facility (TSF).

\subsubsection{Containment materials}

The containment can be built with a variety of materials, including the tailings themselves, mine waste and soil and or rock borrow materials. The selection of the material to be used to build the containment depends on, amongst others:

- Its geotechnical performance - it needs to be dry enough to be placed and to develop enough shear strength to stand up.

- The rate of rise of the tailings beach within the TSF - if the rate of rise of the tailings beach is higher than the rate at which the generated pore pressures are dissipated and strength is gained, then the deposition strategy, wall building technique and allowable production rate need to be revisited.

- The foundation conditions - weak foundations conditions require a more conservative design approach.

- The magnitude of the expected earthquake - where high earthquake loadings are expected the materials used have to be able to continue to perform their design function after undergoing the large strains caused by the earthquake shaking.

\subsubsection{TSF shape}

The shape of the TSF is to a large extent determined by the topography of the site selected (Figure 1).

- In a valley generally only a single dam is required to contain the tailings, although smaller saddle dams may be required on some lower ridges.

- On the side of a hill (a steep slope), walls may only be required the bottom and two sides of the TSF.

- On relatively flat ground containment walls will be required on all sides of the TSF, e.g. ring dyke, turkeys nest.

- In an open pit the containment will be controlled by the lowest elevation at which water will discharge from the pit.

Naturally the volume of material required to build these containments will vary depending on the shape and the height to which they are to be built to contain the life of mine tailings output. 


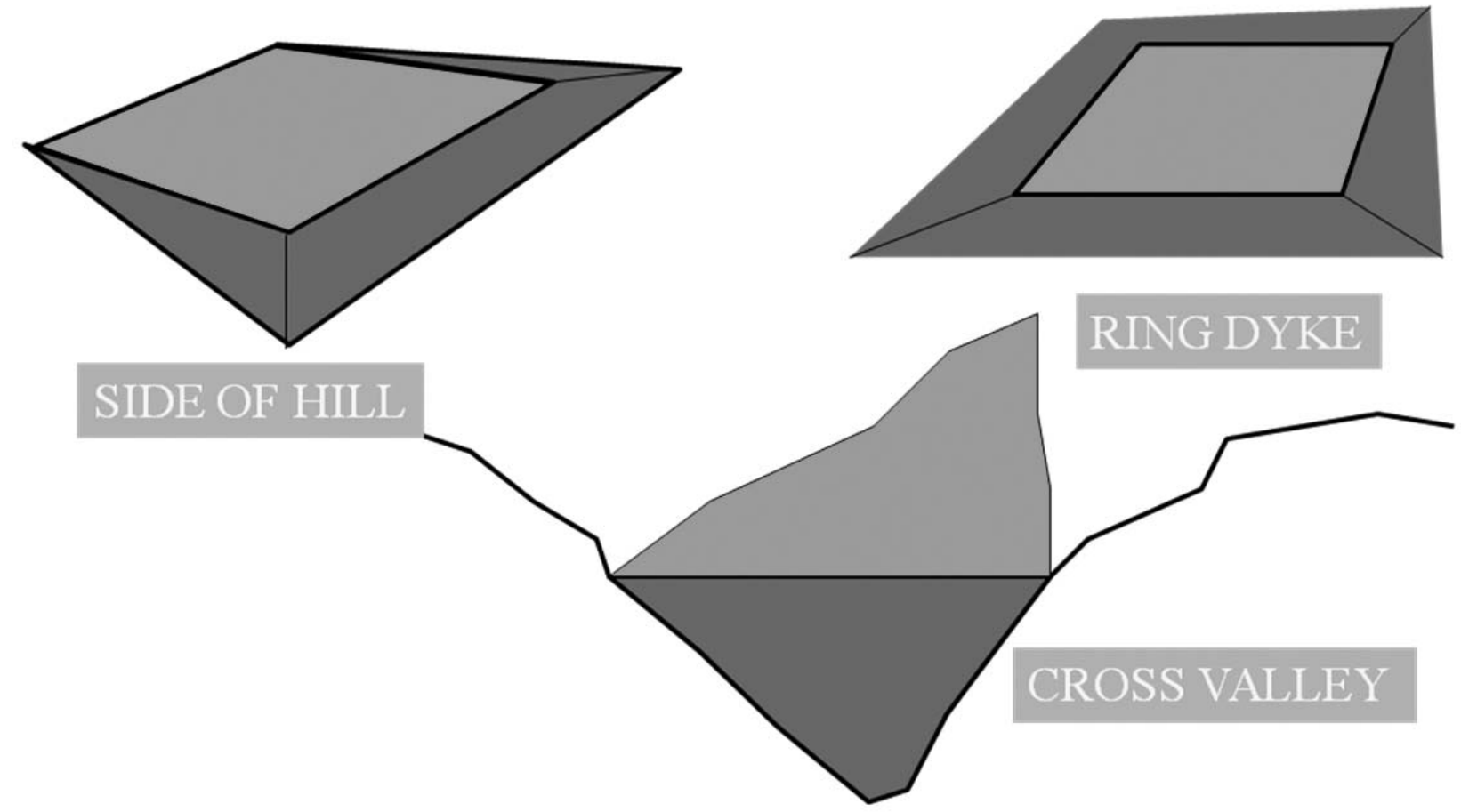

\section{Figure 1 Above ground TSF types}

\subsubsection{Wall building techniques}

Generally, in order to reduce capital costs, the containment walls for a TSF are raised in stages through the life of the facility. The TSF containment walls can be raised using these three wall building directions (Figure 2):

- Upstream:

- Factors that constrain this technique include phreatic surface control, rate of rise of the tailings, storm water storage capacity and susceptibility to seismic liquefaction.

$\circ$ The tailings beach becomes the foundation of the subsequent wall raises.

- It uses the least amount of material to build the walls.

- It is generally limited to specific low earthquake risk areas.

○ Popular in semi-arid areas (such as South Africa).

- Downstream:

- Rate of rise of tailings not a design limitation.

- Uses the most amount of material to build the walls (at a significant cost).

- Allows for storage of significant volumes of water.

- Requires careful advance planning to procure wall building materials.

- Is the most suitable for areas of high earthquake loadings/risk.

- Centreline:

- Compromise between downstream and upstream techniques.

- Uses more material to build the wall than the upstream method.

- Cannot be used for the storage of large depths of water.

- Is more stable under earthquake loadings. 

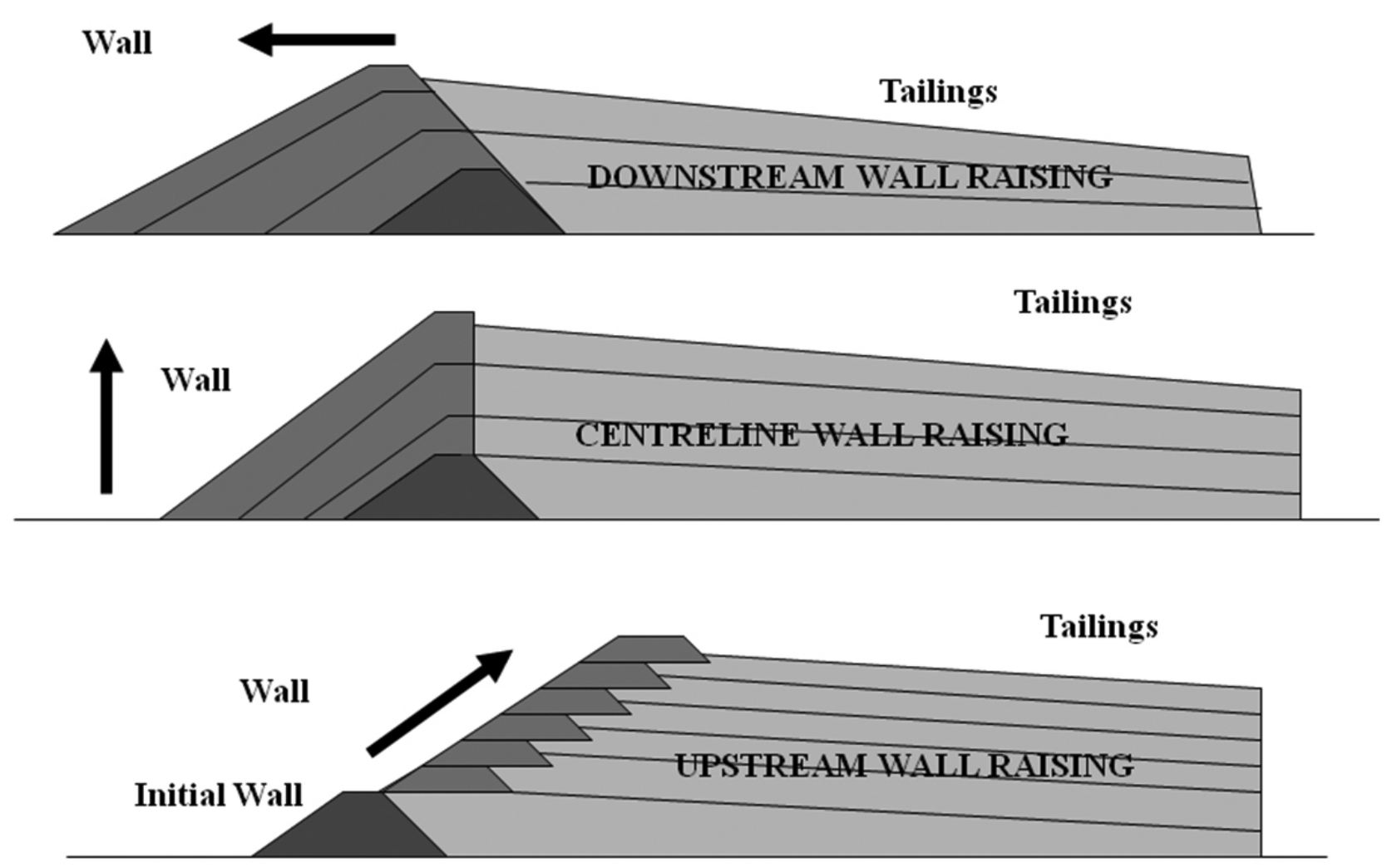

Figure 2 Wall building directions

\subsection{Placement}

The placement method depends to a large degree on the condition of the tailings.

\subsubsection{Conventional slurry}

Conventional slurried tailings are most often deposited sub-aerially, with supernatant water flowing down the beach and accumulating around the decant facility, from where it is, if suitable, returned to the process plant for reuse. The advantage of sub-aerial deposition is that it allows the layers of tailings on the beach to desiccate, thereby increasing their dry density, reducing the storage space required, and increasing their shear strength. However, this method exposes the tailings to wetting and drying cycles, a key component of the AMD cycle. It is thus highly likely that certain tailings material with a PAF propensity will form AMD, with the risk of contaminating both surface (supernatant) and ground (seepage) waters. Alternatively, they can produce neutral mine drainage (NMD) with elevated metal salts that report to seepage. NMD also results from the oxidation of sulphides.

In order to control AMD, PAF tailings need to be typically placed under a water cover to prevent desiccation and the uncontrolled ingress of oxygen. This is difficult to achieve in water deficit climates that exist over much of Australia. It also requires good management to maintain sufficient water cover, generally $>1 \mathrm{~m}$, over the tailings, to limit the mobilisation and oxidation of the tailings through wave action. This means that the deposition point has to be moved continuously to prevent the heaping of tailings above the water surface.

However, while a water cover will substantially reduce the likelihood of acid drainage conditions from forming, there is no guarantee that metalliferous drainage conditions will not occur, so AMD contamination may still be a risk. It should be noted that the containment walls for a water cover TSF may need to be designed to a higher (water-retaining) standard than that required for conventional sub-aerial tailings disposal.

By managing the size of the decant pond and providing sufficient freeboard to cater for the expected rainfall pattern at all times during operation, there should be a very low risk of the supernatant water escaping into the surface waters downstream of the TSF. 


\subsubsection{Thickened and paste}

Thickened and paste tailings are used to reduce the water contained in the tailings slurry (increase the solids content). While a thickened slurry can be pumped using centrifugal pumps, paste generally has to be pumped by a positive displacement pump (diaphragm, peristaltic or piston).

Special thickeners, including deep tank thickeners (DTT) are used to produce the thickened and paste slurries, slurries which offer several environmental advantages over conventional slurries:

- There is little or no supernatant water to deal with on deposition of the tailings.

- While the tailings body may remain saturated, exposed surfaces will desiccate quickly, resulting in potentially higher settled dry densities.

- There is a very low risk of seepage emanating from the tailings as there is no free water driving head.

While paste tailings are usually pumped to disposal, it can also be hauled by truck or transported by conveyor (may cause the material to liquefy) to the disposal site.

The problems of desiccation and oxidation of tailings are exacerbated when materials with increased solids concentration are used, so its application to PAF tailings would be limited to very dry climates where surface runoff is very limited and can be collected and treated easily. Typically, thickened and paste tailings slurries are used when water recovery is critical to the sustainability of the mine. It should be noted that DTTs are currently limited in size to about $30 \mathrm{~m}$ in diameter (compared with $200 \mathrm{~m}$ diameter conventional thickeners). Thus their throughput is limited and a large number would be required to accommodate large tailings throughputs, such as the $>300,000$ tpd of dry solids for copper mines in South America.

\subsubsection{Filtered tailings}

The ultimate process is to dewater tailings using some form of filtration to produce a tailings filter cake. The types of filtration used include:

- Vacuum belt filtration - most efficient on coarser materials.

- Belt filtration - used on a range of materials.

- Vacuum leaf filters - used on a range of materials.

- Plate and frame presses - used primarily on fine-grained materials and for water treatment sludge.

- Tube press - used on very fine-grained materials and where a very dry cake is required.

The cost of filtration generally increases from type 1 through type 5. Once filtered, the cake can be conveyed or hauled to disposal, facilitating a range of disposal options.

The production of a tailings filter cake does not necessarily reduce the risk of AMD. In fact it can result in the very opposite, as the filter cake quickly becomes partly saturated, presenting ideal conditions for the formation of AMD. While the seepage and runoff can be limited and controlled in very dry climates (such as in Chile and arid Western Australia), this may not be possible in the more temperate or tropical regions of Australia.

Experience in a very dry climate has in fact shown that the high suctions existing in the soils under a filter cake stack can draw water from the near-saturated filter cake and lead to unexpected and significant AMD plumes in the ground under the stack.

It is of note that there is a growing trend in China to ban the use of a TSF for tailings and force mines to use filters to dewater tailings prior to deposition.

\subsection{Seepage}

Throughout the life of a TSF seepage will occur. The seepage is driven through the deposited tailings by an hydraulic gradient generated by the water held in the decant pond. 
Seepage water will flow out through the:

- Containment walls - to contaminate surface waters

- Base of a TSF - to contaminate groundwater.

Seepage is likely from all deposited slurried tailings, even after consolidation, where the permeability may be in the range of 10-6 to $10-8 \mathrm{~m} / \mathrm{s}$. After some consolidation tailings may eventually develop a very low permeability (down to $<10-9 \mathrm{~m} / \mathrm{s}$ ), but even at this permeability flow will still occur into the underlying natural ground, and/or through the containment wall, although at a greatly reduced rate. For this reason many jurisdictions now require the TSF to be lined using either a natural clay or a geomembrane. However, there is no such thing as a 'leak-proof' liner, and hence no such thing as a leak-proof TSF. Seemingly intact geomembranes with an intact permeability of $<10-14 \mathrm{~m} / \mathrm{s}$ may in fact have an actual permeability three or more orders of magnitude greater than this, due to poor installation practices and poor quality control and assurance procedures.

When deposition ceases seepage is likely to continue for a number of years, as the phreatic surface within the tailings drops, until such time as the hydraulic gradient is balanced. Note that seepage may continue indefinitely if rainfall recharge is large enough to maintain the phreatic surface.

Present day TSFs are usually large structures containing millions of tonnes of tailings and a large volume of water in the tailings voids (pore fluid). In a TSF located in a semi-arid environment the tailings supernatant water will migrate from the TSF into the underlying geological environment during the life of mine and, following mine closure, will develop an unsaturated tailings zone at the surface. This unsaturated zone which can be tens of metres thick will, if it contains iron sulphides, undergo gradual oxidation and generation of AMD. Annual fresh water inputs after mine closure into the unsaturated zone will continue to transport contaminants to the base of the TSF.

Reducing contaminated seepage is a key environmental consideration in the design of a TSF, particularly if the seepage has the potential to be AMD. Methods to reduce the volume of free water deposited with the tailings, using thickened, paste or filtered tailings, and by better decant pond management, are being used more widely to manage seepage and reduce infiltration, but there is little data to indicate whether this managing AMD or is really aimed saving water. It is a favourable combination really in that the conservation of water has another positive environmental affect.

\subsection{Lining the tailings facility}

The seepage component of the AMD stream can be controlled, but not eliminated, by lining the tailings facility (whatever its type). Each of the liner types shown below has its particular attributes that make it attractive as a liner for particular applications:

- Natural clays.

- Geomembranes:

○ Rubber.

- Polyvinyl chloride (PVC).

- Geosynthetic clay liner (GCL).

$\circ$ High density polyethylene (HDPE).

○ Poly-flex linear low density polyethylene (LLDPE).

- Bitumen impregnated geotextiles.

Lining is expensive, typically costing $>\$ 15 / \mathrm{m}^{2}$, so for a TSF covering 50 ha the cost would be in the order of $\$ 7.5$ million.

Adding a liner adds other complications to a TSF. Natural seepage, which aids in controlling the level of the phreatic surface, can no longer occur through the liner, so if required, extensive underdrainage has to be installed to control the level of the phreatic surface. If no underdrainage is included the allowable rate of rise 
of the tailings will be reduced, as downwards drainage cannot occur. Alternatively the tailings could be contained within fully engineered walls, where the rate of rise would not be constrained.

Synthetic liner systems that are used in the mining industry, as listed above, have an expected life of about 50 to 100 years. Once the AMD process commences in unsaturated tailings, it can continue for hundreds of years, which is much longer than the life expectancy of synthetic liners. So having a liner system in the basin of a TSF does not guarantee the containment of AMD 'forever'.

\section{Waste rock}

Waste rock dumps are also a major source of AMD when there are PAF materials in the waste. The sources of AMD are both:

- Surface runoff, which occurs during and immediately after rainfall.

- Seepage flows, which typically lag rainfall events and emanate as pulses of low ph water.

The generation of AMD from waste rock dumps can be controlled by identifying the in situ characteristics of the PAF and non acid forming (NAF) waste materials and then managing their placement so that the NAF waste is used to encapsulate the PAF waste.

\subsection{Air voids}

Typically dumps built with relatively fresh waste rock have a porosity of around $30 \%$ that is there is a considerable void space between the pieces of rock. One of the biggest problems with managing AMD in fresh waste rock is that the voids between the rock fragments create an ideal pathway for air and water to pass, air that will oxidise the iron sulphides and water that will convey the oxidation residues in an AMD stream. This problem is exacerbated when waste rock is end-dumped down high advancing dump faces, where the coarser material ravels to the base of the dump and the finer material is held up higher on the slope. The coarse base rubble zone provides easy air entry to oxygenate the dump.

In practice, the air voids can be limited to some extent by the careful placement compaction of the waste in thin layers. This is not easy to achieve as the waste rock is generally randomly-sized over a large size range. However, by optimising blasting patterns and charges, the oversize can be limited and a preferred top-size can be achieved. In extreme cases where there are predominately larger rocks, thicker layers can be used by using dynamic compaction, using a 'square' impact roller.

\subsection{Filling waste rock voids}

It would be possible to eliminate the need to compact the waste rock if the air voids could be filled with another material, such as a tailings product. In this way the tailings forms a low permeability/transmissivity barrier to the ingress of water and air, limiting the potential generation of AMD from the waste rock. This is not as easy to achieve in practice as it seems, and methodologies are discussed below.

\section{Co-disposal}

A number of terms are used to describe a co-disposal process, each of which indicates slightly different approaches to handling and disposal of waste materials:

- Co-disposal - coarse and fine waste products are mixed together before transportation to the disposal site. An example of this is the pumped co-disposal of coarse reject and tailings washery wastes practiced at a number of Australian coal mines in the Bowen Basin.

- Co-placement - coarse and fine waste products are transported separately and mixed together just prior to or on placement at the disposal site. An example of this is the mixing of slimes and tailings used previously at the Argyle Diamond Mine.

- Co-mingling - coarse and fine waste products are transported separately and allowed to mix together within the disposal site after deposition. This is a growing practice in Bowen Basin coal mines, and was used at the Kidston Gold Mine to dispose waste rock and thickened tailings (Figure 4). 


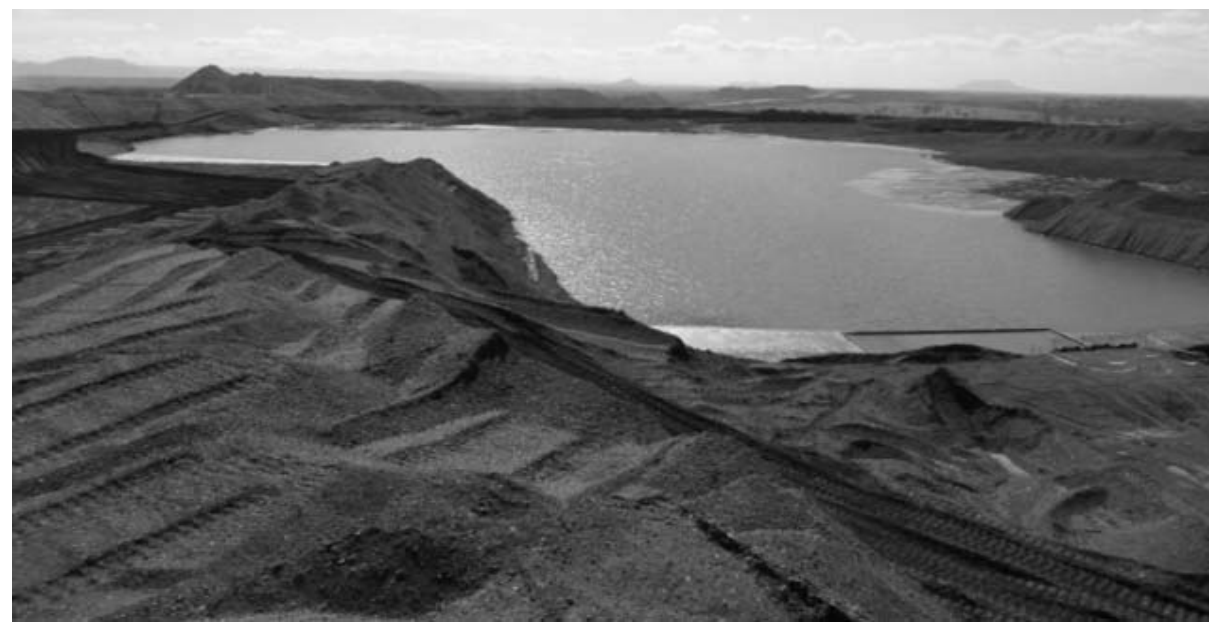

Figure 3 Pumped co-disposal - coarse rejects containment with tailings contained in the middle

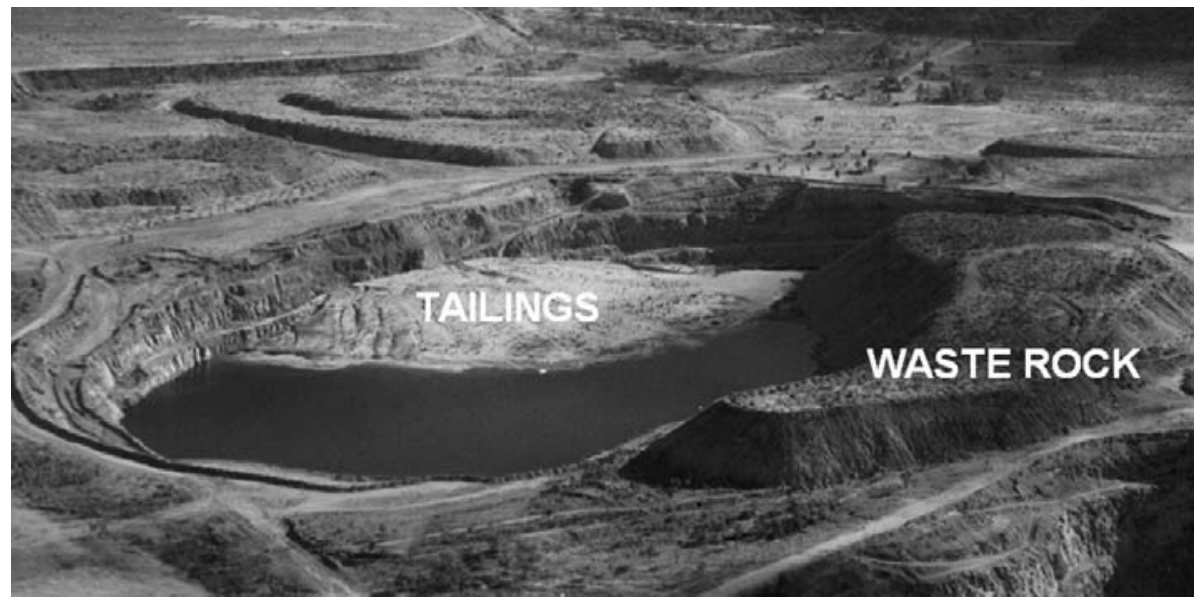

\section{Figure 4 Kidston co-mingling}

\subsection{Concrete mix - ideal co-disposal}

A concrete mix represents ideal co-disposal, consisting of a blend of aggregate (coarse) and a sand/cement mix (fines), which are thoroughly mixed with a very limited volume of water. A typical 3:2:1 aggregate:sand:cement concrete mix would have a water:cement ratio of 0.35 . The resulting paste-like mixture is poured or pumped into formwork (in mining terms think of the formwork as a TSF containment).

What is found when a block of concrete is cut open is the coarse aggregate suspended in the sand and cement fines, with the individual pieces of aggregate rarely touching (Figure 5).

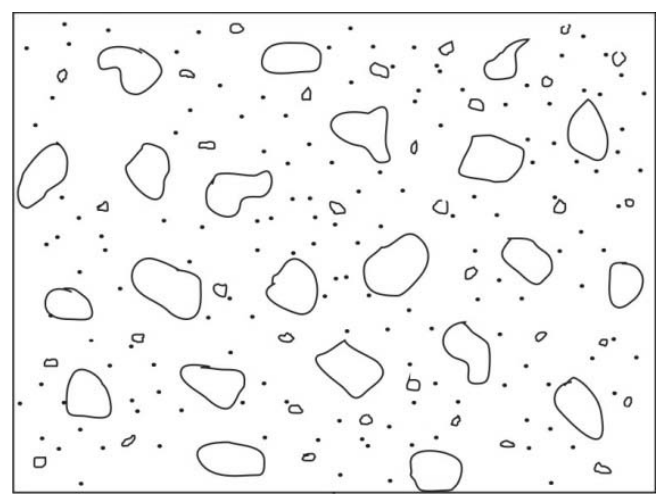

\section{Figure 5 Concrete mixture}




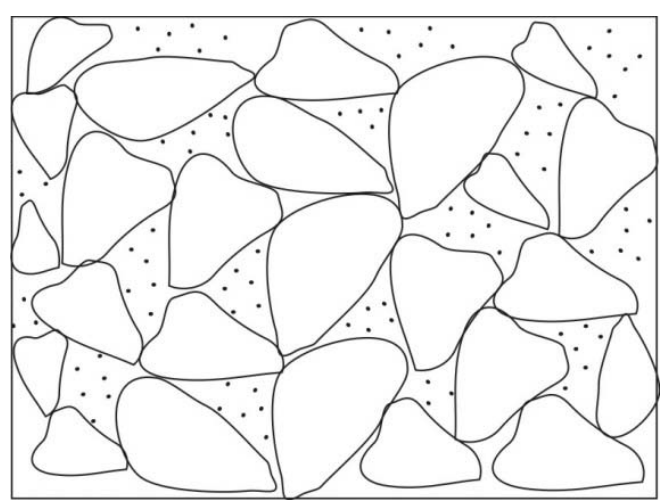

Figure 6 Co-disposal mixture

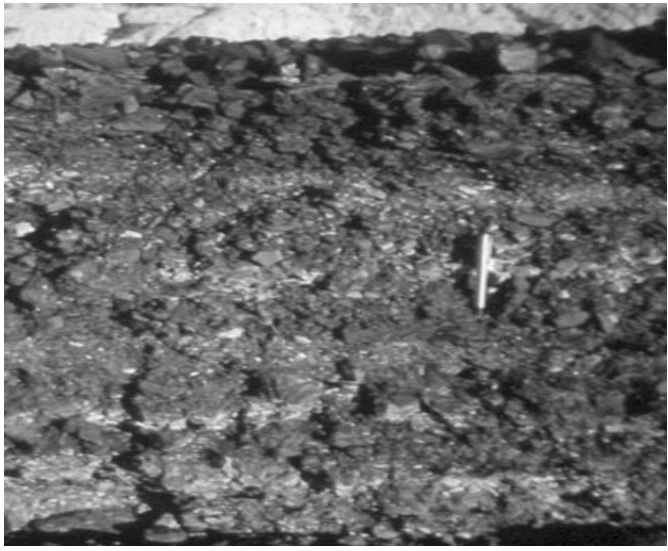

\section{Figure 7 Co-disposal beach section}

In concrete, the coarse aggregate can remain suspended in the fine matrix as the cement bonds them all together and provides the shear strength required to support the loads applied. However, with a mixture of coarse and fine mine wastes there is no such binder and so, if there is a need to maintain the shear strength of the mixture, so as to safely achieve the heights required or to maintain trafficability, the coarse particles need to stay in contact. In other words only the available void space should be filled so that the coarse particles are not forced apart (Figures 6 and 7), for then the shear strength of the tailings will control the stability of the dump.

\subsection{Introduction of tailings}

If the air voids between waste rock particles could be filled with finer-grained tailings, the air and water transmissivity of the resulting mixture would be reduced and its propensity to generate AMD would also be reduced. While the tailings are likely to have a far higher porosity than the waste rock ( $50 \%$ versus $30 \%)$, the voids provide a tortuous path for both air and water under gravity flow.

\subsection{PasteRock ${ }^{\circledR}$}

PasteRock ${ }^{\circledR}$ describes the ideal mixture of thickened or paste tailings and waste rock. A predetermined ratio of benign tailings is used to fill the air voids in a PAF waste rock in order to reduce the transmissivity (air and water) of the waste, thus reducing the propensity of the waste rock to produce AMD conditions. PasteRock has specific applications in the development of a low transmissivity cover for a PAF waste rock dump, where a controlled thickness and limited volume of material is required to form the cover.

An earlier version of this method was developed by Golder in South Africa for use as a closure cover for the Daggafontein Gold TSF in Johannesburg (J. Wates, 2007, written comm.), a tailings with a low AMD potential. A layer of clean rock was placed on a depth of soil, and the two materials were then excavated and loaded into trucks and hauled and dumped (Figure 8), facilitating mixing, for use as a cover on the TSF 
slopes. Final mixing was achieved by dozing prior to seeding (Figure 9). Results have been very good to date for this site located alongside a RAMSAR stream.

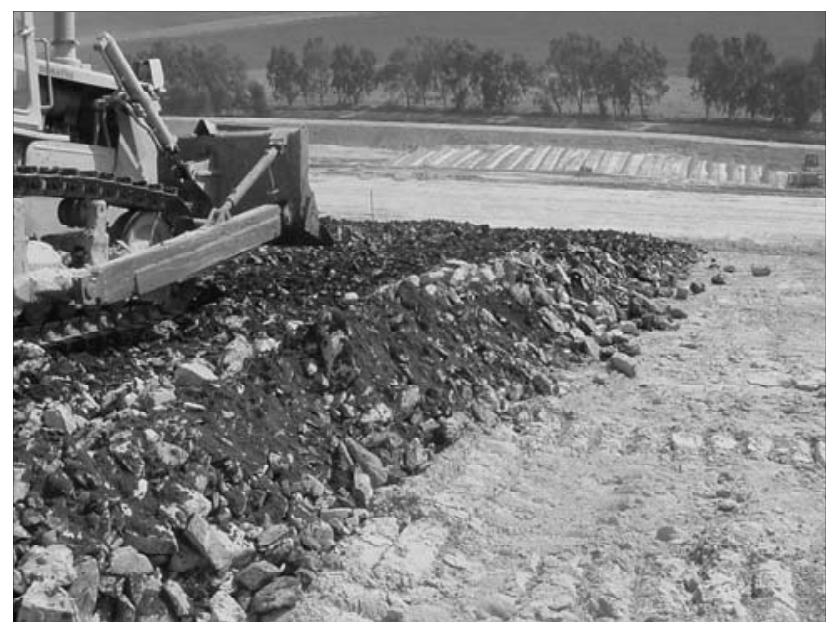

\section{Figure 8 Placing rock-mulch cover}

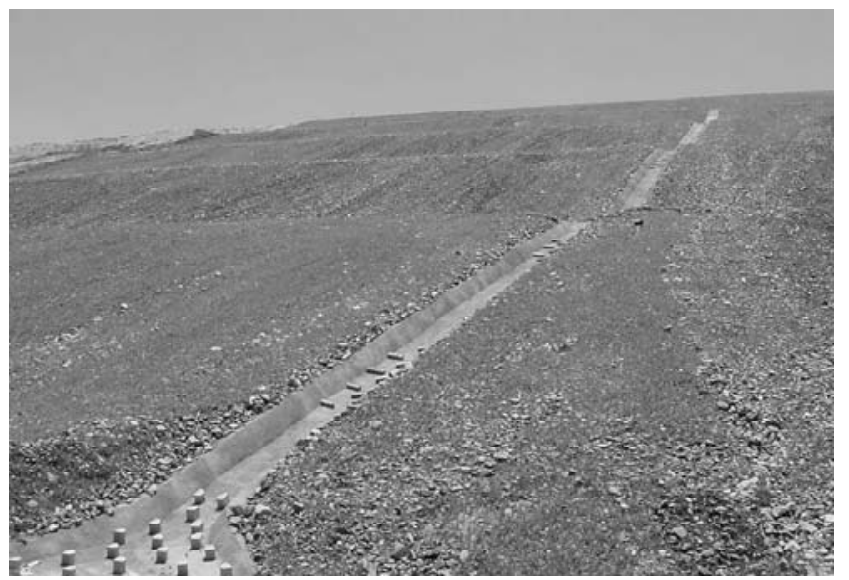

Figure 9 Cover with hydro seeding

Several trials have been carried out on PasteRock at mine sites with and without additives such as calcium carbonate, gypsum and bentonite to test their performances as engineered cover layers over PAF waste rock and tailings. In the future variants of this cover type can be trialled at mine sites to test performance against engineered cover objectives established for particular requirements. This includes testing as a store and release cover.

To date PasteRock has not found wide application in mine waste disposal application, due to the difficulty in practice of mixing the tailings and waste rock (and additives), in the volumes and at the rates produced by mines. The balance of this paper discusses potential ways of combining tailings and waste rock to reduce the AMD potential of both.

However, by using the Daggafontein model, instead of the slurried tailings methods trialled to date, PasteRock would be feasible. It is envisaged that special shallow cells could be filled with 0.5 to $1 \mathrm{~m}$ of tailings, and after a period of desiccation, the waste rock could be layered over the tailings and then the two materials excavated and hauled for placement as a cover.

\subsection{Co-disposed mine wastes}

Ideal co-disposal can rarely be achieved in mining, in which there is rarely the opportunity to select or size the constituents and their proportions, and these often vary over time. Co-disposal has to be made to work with the constituents and their proportions resulting from the mining and metallurgical processes. 


\subsubsection{Porosity}

The governing factor in co-disposal is the void space or porosity available between the coarser particles, which can be filled with water, finer solids or air.

Table 1 indicates some typical values of the physical characteristics of the waste products of coal mining and processing.

Table 1 Physical characteristics of coal wastes

\begin{tabular}{lccc}
\hline Characteristic & Spoil & $\begin{array}{c}\text { Coarse } \\
\text { Reject }\end{array}$ & Tailings \\
\hline Specific gravity & 2.7 & 2.2 & 1.8 \\
Dry density $\left(\mathrm{t} / \mathrm{m}^{3}\right)$ & 1.8 & 1.5 & 1.1 \\
Void ratio & 0.50 & 0.47 & 0.64 \\
Porosity & 0.33 & 0.32 & 0.39 \\
Saturated gravimetric moisture content $(\%)$ & 19 & 21 & 35 \\
Ideal coarse:tailings ratio & 4.9 & 4.3 & \\
\hline
\end{tabular}

Generally, the best that can be achieved with co-disposal is filling the void space of the coarse wastes products with tailings. The ratio of coarse material to dewatered tailings is ideally greater than $4: 1$, as shown in Table 1. Any more than this and:

- the characteristics of the tailings start to modify the behaviour of the coarse waste

- handling of the combined materials becomes more difficult.

The actual proportion of coarse:fine material is generally dictated by the ore, particularly in the case of coal mining, and ranges from better than $4: 1$ to as low as 1.4:1. The mixture ratio is critical to the efficacy of the co-disposal system, for the lower the ratio the lower the theoretical percentage of tailings that can be contained within the voids between the coarse rejects particles, as shown in Figure 6. In practice, the low percentage solids at which co-disposed coal washery wastes are pumped and the high pumping velocity used result in considerable washout of fines and the theoretical containment of tailings is not achieved.

The effect of the coarse:fine ratio on the potential percentage of excess tailings (those that cannot be contained within the coarse reject voids, relative to the total tailings tonnage in the co-disposal stream) is shown in Table 2 (based on a coarse specific gravity (SG) of 2.0, a tailings SG of 1.8, a dry density for the co-disposal beach of $1.72 \mathrm{t} / \mathrm{m}^{3}$ and $0.8 \mathrm{t} / \mathrm{m}^{3}$ for the tailings).

Table 2 Variation of excess tailings with varying coarse:fine ratio

\begin{tabular}{cc}
\hline Coarse:Fine Ratio & Excess Tailings (\%) \\
\hline $1.4: 1$ & 74 \\
$3: 1$ & 34 \\
$5: 1$ & 6 \\
\hline
\end{tabular}

\subsubsection{Mixing}

The problem with mine wastes is many-fold, including:

1. The waste and rejects are handled in different ways, often located kilometres apart.

2. The tailings are generally saturated and have a low shear strength.

3. There is generally insufficient void space in the coarse waste to absorb all of the tailings.

4. The waste stream and the particles are too large to mix in a conventional mixer. 
Mixing the coarse waste and the tailings mechanically before placement, as with concrete, is not a viable option for mining. Other solutions have to be found if mixing is to be used.

\subsection{Co-disposal applications}

Coal mines, in particular, have trialled and used co-disposal for years. Back in the 1960s, the British Coal Board carried out tests that involved the spreading of coarse reject and then the pouring of tailings slurry over the reject (M. Williamson, 1998, written comm.). Similar trials were carried out in South Africa, but were discontinued when it was found that:

- The coarse reject had to be placed in very thin $(<200 \mathrm{~mm})$ layers to get a reasonable depth of tailings penetration.

- The cost of placing the coarse reject in thin layers and distributing the tailings was prohibitive.

The most successful application of co-disposal, coarse and fine waste streams - coarse reject $60-1 \mathrm{~mm}$ and tailings $>1 \mathrm{~mm}$ to clay sized, is the pumped co-disposal used in a number of Australian coal mines. The coarse reject and fine tailings streams are combined at the preparation plant (CHPP) and pumped to a storage facility for disposal. The slurry mixture is typically pumped at around $25-30 \%$ solids at a line velocity in excess of $4 \mathrm{~m} / \mathrm{s}$ (in contrast to flow rates normal slurries of around $2.5 \mathrm{~m} / \mathrm{s}-$ in order to limit the risk of clogging). On deposition, a high percentage of the fine tailings flow down the steep combined rejects beach and into the tailings pond. This is due to the combination of stream energy and a physical limitation on the volume of void space available within the coarse reject to store the tailings.

\subsubsection{Jeebropilly}

In 1990, Jeebropilly Colliery west of Ipswich in South East Queensland managed to get a coal washery reject co-disposal system up and running as a means of overcoming the handling problems they were experiencing with their coarse reject, which weathered rapidly on exposure. They deposited the co-disposal into a final void and found that the system provided them with a low cost and successful means of transporting their waste streams.

On the basis of this work and the publicity co-disposal received from an Australian Coal Association Research Program (ACARP) research project undertaken by Professor David Williams of The University of Queensland, the co-disposal system became accepted practice in Australian coal mines.

\subsubsection{Where has pumped co-disposal been used?}

Co-disposal is used most widely in the coal mining industry and only occasionally in the metalliferous industry. The coal mines that are known to use (or have used) pumped co-disposal include Burton, Charbon, Coppabella, Cumnock, Hail Creek, Kestrel, Moorevale, Moranbah North, North Goonyella, Stratford and others. It is also used at Indonesian coal mines.

\subsubsection{Advantages of co-disposal}

Some of the advantages of co-disposal are:

- No surface fleet is required to haul coarse reject.

- The co-disposal material can be used to build the containment, using upstream wall building methods.

- The mixed coarse reject:tailings co-disposal material can be trafficked immediately after, and sometimes even during, deposition.

- The footprint required for co-disposal is smaller than that of separate coarse reject and tailings facilities.

- Water losses can be lower than for separate disposal systems. 


\subsubsection{A typical co-disposal system}

A typical co-disposal system consists of the following components:

- A tailings thickener, which is often not used to maximise underflow density.

- A reject hopper to manage the flow of reject to the co-disposal system.

- A co-disposal mixing tank into which the two waste products are introduced and make-up water added.

- A multi-staged, high head pumping system to drive the mixture to the storage site.

- Lined pipes (basalt or ceramic) for some distance to reduce wear.

- A co-disposal storage facility, which could be on the surface or in-pit.

\subsection{Disadvantages of pumped co-disposal}

There are some very real disadvantages to pumped co-disposal, as listed below:

- Considerable energy is required to pump the co-disposal slurry to the storage and to return the water recovered to the plant for reuse.

- High maintenance input is required to maintain pumps and pipelines.

- It is in reality another form of tailings disposal; it does not develop a stack as is achieved with spoil and waste rock, and needs to be managed using tailings disposal management principles.

- Generally, less than $50 \%$ of the tailings are retained on the co-disposal beach, so that a major tailings pond develops.

- If the coarse:fine ratio is low, there may not be enough co-disposal beach material to build the containment walls.

- There is a large volume of water in circulation with conventional pumped co-disposal and, if water management is not tight, it is very easy to lose a large percentage of this water.

\subsection{Co-mingling}

Co-mingling, possibly the easiest form of co-disposal, is where the coarse and fine waste streams are handled separately and allowed to mix or mingle on placement. In this system, there is no positive mixing and while it is a desired result, mixing is not essential to the success of the system.

Two examples of co-mingling are:

- Tarong Coal Mine - a final void was filled with reject, end-dumped and spread from along the rim of the void and tailings pumped into the void

- Kidston Gold Mine - waste rock from a new pit was end-dumped over the rim of a completed pit and thickened tailings were deposited from a location further around the pit. The tailings were allowed to flow into the toe of the waste rock face, which was advanced by end-dumping from the crest without any major incidents (Figure 4).

\subsection{Co-placement}

The coarse and the fine waste products are transported separately to the deposition site, where they are either mixed together prior to deposition or the tailings is deposited into cells created within the waste rock dump. There are a number of variations of this system, as discussed. 


\subsubsection{Autogenous mixing}

The tailings are discharged over the edge of the waste rock dump and allowed to mix with the waste rock as it travels down the face. While this system sounds low cost, there are some distinct disadvantages:

- The tailings slurry pipeline has to be kept out of the way of the waste rock haul equipment and moved continuously as the dumping point and waste dump face move.

- Unless a tailings paste is used, most of the tailings slurry is likely to end up at the base of the waste rock dump, resulting in little mixing and possibly leading to continual dump instability.

- There will be water management issues with the large volume of tailings supernatant water that will have to be handled at the base of the dump.

Examples of where this system has been used are:

- Mt Thorley - used for many years, the tailings were dewatered on belt filters, added to the coarse reject on a conveyor, and transported in trucks to be dumped over the low wall at the same time as the mining spoil.

- Argyle - the tailings were discharged with the fine reject at the end of a conveyor belt, to allow autogenous mixing as the products flowed into the TSF.

\subsubsection{Active mining}

The tailings are discharged at the point of waste rock dumping, and then actively mixed by bull-dozing the two products together. The disadvantages of this system are:

- The tailings slurry pipeline has to be kept out of the way of the waste rock haul equipment and moved continuously as the dumping point and waste dump face move.

- There is an added cost of dozing to achieve mixing.

- Ideally, a tailings paste needs to be used to provide a stockpile of tailings at the discharge of the pipeline.

\subsubsection{Windrowing}

Windrowing is a method where the waste rock is dumped in windrows some metres apart, the tailings are deposited into the space between the windrows, and then the windrows are dozed to provide a mixture of tailings and waste rock. In this system, it would be easier to keep the tailings pipeline clear of the mining operations, but it has the following disadvantages:

- The additional cost of waste rock placement and dozing.

- Potential issues with the tailings supernatant water.

\subsubsection{Cells}

Cells for the containment of tailings within the waste rock dump are particularly attractive when the tailings have a potential to generate AMD, and the waste rock has an acid neutralising capacity. As the name implies, cells are established in the waste rock dump as it is built, which are filled with tailings and then capped with waste rock to fully encapsulate the tailings. This is similar to the encapsulation system used to contain AMDgenerating waste rock.

In most instances, the additional cost of building and capping the cells would be less than the alternatives of building a lined TSF.

Deposition in cells was used for many years in the Illawarra Coalfields to dispose of coarse reject and tailings, to form a stable waste landform. The cells were constructed of coarse reject, filled with tailings slurry and then covered over with coarse reject before the next cells were constructed on top. 


\subsection{Handling mixed wastes in practice}

In mining practice it is very difficult to achieve the degree of mixing required to make a co-disposal solution. The coarse and fine products are generally produced far apart, maybe many kilometres apart, the fine product (tailings) is generally in a slurry form, and a system to mix them efficiently on a mining scale has not been manufactured yet.

Even where the products are geographically close together, achieving the degree of mixing at the dump face will require a considerable amount of mechanical input. As noted pumped co-disposal which produces the full mix of the coarse and fines products, loses this advantage on deposition as a large percentage of the tailings ends up in the tailings pond.

The most efficient system to date has been when a conveyer is used to transport the coarse product on to which the tailings is dropped, with mixing taking place on the belt and on dumping (such as at Mt Thorley coal mine). So where conveyer systems are installed for overburden, such as in some coal mines, the process reject materials could be added to this belt for a true co-disposal solution, noting of course that the tailings would first have to be dewatered sufficiently.

In view of these difficulties we suggest that the most practical method of achieving co-disposal of waste would be to:

- use the encapsulation system, where the tailings are contained in cells constructed within the waste dumps

- develop as covers for TSF and waste rock landforms with or without additives such as calcium and magnesium carbonate, gypsum and bentonite.

These applications are likely to have positive outcomes for the management of AMD.

\section{$5 \quad$ Trends}

There is a growing movement in the Queensland coal mines towards the disposal of dewatered tailings with the rejects in a stand-alone dump or with the mine waste in dumps, using either the settling pit of filter systems. However, the Queensland DERM is placing a limit on the physical characteristics of the tailings that can be placed in a stand-alone dump, requiring a residual shear strength of 1,000 Pa. This may not seem a very high number, but it should be compared with a generally accepted maximum yield stress for a paste of around $400 \mathrm{~Pa}$, which would eliminate the use of thickened tailings and place a requirement for a high efficiency from filtration. Testing of a dewatered coal tailings and a co-mingled mixture is currently underway to investigate the range of yield and residual shear strengths that can be achieved.

\section{Conclusion}

Water conservation is a driving force in the management of tailings. Over the past 12 months China has taken steps to force mining companies to reduce the amount of water in discharged tailings through the use of filtration. It may not be long before we see, world-wide, the discontinuation of the wet slurry disposal of tailings. This will force the industry to look more closely at co-disposal techniques and the associated cost and benefits, including the management of AMD.

Tailings solids in a TSF are often a source of AMD or neutral drainage, containing contaminant levels that do not meet national discharge criteria. Commonly, the quality of pore fluid and supernatant water in a TSF may not meet the criteria. These two attributes contribute to the need to manage TSFs for a very long time. Reducing the amount of water that will leak from a TSF will reduce the cost of long term management. Thickening tailings is a means of reducing the leakage.

Present day TSFs are usually large structures containing millions of tonnes of tailings solids and an equivalent volume of pore water and supernatant mixed with fresh water at the surface. During the mining operation in a typical TSF located in a semi-arid environment the tailings supernatant water will infiltrate from the TSF into the dam wall and also into the underlying geological basement. Following mine closure an unsaturated tailings zone will develop at the surface. This unsaturated zone which can be tens of metres in thickness will, if it contains iron sulphides, undergo gradual oxidation and generation of AMD. Annual fresh 
water inputs after mine closure into the unsaturated zone will continue to transport contaminants to the base of the TSF. Synthetic liner systems that are used in the mining industry and which have been described in this paper have an expected life of about 50 to 100 years. Once the AMD process commences in unsaturated tailings, it can continue for hundreds of years, much longer than the life expectancy of synthetic liners.

Tailings disposal remains a significant input for a mining operation and a very real challenge for closure, especially when there is a risk of groundwater contaminated seepage due to the migration of AMD. The long term generation of AMD is dependent on the geochemical character of the tailings and the entry and transport of water and oxygen through the tailings from top to bottom of the system. Reducing the water content in tailings and limiting the infiltration of water and oxygen through the surface of the TSF is the key to long term success in management of AMD. At mine closure the function, design-build and effectiveness of the TSF cover is the key component to be considered. The application of surface engineered covers such as synthetic liners or a suitable co-disposal system can limit the development of AMD in a TSF. These surface covers and their maintenance or replacement can be costed for the purpose of estimating long term financial management of a facility following mine closure. Managing AMD after mine closure depends to a large extent on the performance of the cover. The physical constraints on achieving a co-disposal solution (e.g. PasteRock) and the associated costs may limit its use to a few mines with specific circumstances. We recommend that the mining industry continue to carry out research and development into these potential cover systems. 